\title{
Violências de gênero: assassinos/as impiedosos/as ou enlouquecidos/as pela dor do amor?
}

\author{
Nunca você sem mim: homicidas- \\ suicidas nas relações afetivo- \\ conjugais.
}

TEIXEIRA, Analba Brazão.

São Paulo: Annablume, 2009. 192 p.

Em tempos de Lei Maria da Penha, a violência de gênero ganha maior visibilidade junto à sociedade civil e reconhecimento, por parte do Estado brasileiro, dos diversos problemas que são gerados em consequência de tais atos.

Há muito que pesquisadoras e a militância feminista se debruçam sobre o tema para mostrar as faces e interfaces das variadas violências que atingem as mulheres, e para marcar um espaço de luta em busca de proteção dos direitos humanos, direitos das mulheres. Várias foram as conquistas no campo das políticas públicas: criação das delegacias das mulheres, em 1985; promulgação da Lei Maria da Penha (Lei 11 .340), em 2006;' e, em 2009, promulgação da nova Lei do crime de estupro (Lei 12.015), ${ }^{2}$ que altera a redação de alguns crimes sexuais previstos no Código Penal Brasileiro. Essas e outras alterações têm contribuído para que a violência perpetrada contra as mulheres saia do espaço privado e se insurja na tela dos espaços públiços com tonalidades de indignação e cores de esperança. Esperança de que essas práticas deixem de fazer parte das estatísticas institucionais e que o reconhecimento dos direitos das mulheres esteja na pauta de toda a sociedade.

"Nunca você sem mim..." é a frase que abre o título do livro de Analba Teixeira Brazão, que, em difícil análise de tema tão complexo, lança mão da poesia e evoca a ciência para apresentar sua pesquisa sobre grupo que ela denomina de "homicidas-suicidas" nas relações afetivo-conjugais. A autora percorreu um trajeto espinhoso para trazer ao conhecimento da comunidade científica e do movimento feminista uma pesquisa inovadora, detalhada e corajosa evidenciando relações que envolvem sentimentos afetivos e que terminaram em tragédia.

A originalidade do livro está em analisar não só os aspectos relacionados às mulheres que tiveram suas vidas ceifadas por seus companheiros. Apresenta, também, o caso de um homem que foi vítima de sua companheira. Utiliza como ferramenta teórica as contribuições de pesquisadoras como Maria Filomena Gregori e Miriam Pillar Grossi, que "buscam compreender a violência de gênero como algo relacional", na qual a mulher e o homem devem ser localizados socialmente como sujeito na relação. Portanto, Analba se contrapõe a outra concepção, presente nos estudos e militância feminista, de que o homem sempre será o agressor e a mulher estará definitivamente no espaço destinado à vítima.

O caminho escolhido e seguido pela pesquisadora parte de uma discussão teórica abrangente sobre violência de gênero, honra, masculinidades e feminilidades numa perspectiva socioantropológica. A literatura utilizada, além de muito vasta e rica para entender o tema apresentado, possibilitou também um debate teórico que, aliado à pesquisa de campo, procurou responder a questões pontuadas pela autora. Entre elas, por exemplo, quais as razões que levavam as pessoas a matar seus companheiros, companheiras, porventura filhos e filhas e depois cometer o suicídio? Seria a honra, a vergonha e/ou a culpa sentimentos que poderiam surgir a partir da suspeita de uma traição, motivos para cometer o homicídio-suicídio? A autora constata que, para muitas dessas pessoas, existir sem a presença do/a outro/a é impossível.

O locus de estudo da autora é a capital do Rio Grande do Norte, no período de 1995 a 2002. Para realizar a pesquisa, ela utilizou como fontes jornais, inquéritos policiais e entrevistas com familiares e duas das vítimas diretas dos casos selecionados para análises (a filha de um dos casais apresentados nas narrativas e uma mulher que sobreviveu a tentativa de homicídio).

$O$ contato com as fontes possibilitou $O$ amadurecimento da pesquisa. Nesse sentido, trabalhou primeiro com o estudo dos jornais, nos 
quais pesquisou notícias relacionadas a homicidas-suicidas. Continuou analisando outras fontes, como os inquéritos policiais, através de levantamentos realizados nas delegacias da mulher, e buscou os prováveis processos que foram abertos nas varas criminais da cidade de Natal. No entanto, constatou que tais processos não existiam, pois o autor do homicídio praticava o suicídio em seguida. Inquieta com as fontes documentais pesquisadas, a autora foi além: realizou trabalho de campo entrevistando também os familiares das vítimas, quando então se aproximou efetivamente da compreensão de seu objeto.

A análise dos casos respeitou a contextualização dos mesmos, abordando aspectos socioeconômicos dos casais. Contrapondo e aliando as fontes, Analba chega ao ápice de sua pesquisa narrando as histórias. Os personagens Cris e Cesar; Eliana e Gustavo; Suzana e Luciano; Leila e Zito e Silvia e Mauro são retratados no capítulo intitulado "Histórias de amor e morte: eu não existo sem você, como você pode existir sem mim?". Numa trama que envolve personagens com experiências de vida diferentes, vamos a cada página nos envolvendo, nos emocionando e nos chocando com os fins trágicos.

Não contaremos todos os casos do livro, mas para aguçar a curiosidade do/a leitor/a escolhemos para relatar a história de Suzana e Luciano. Através da entrevista com a filha, Andréia, sobrevivente do crime, e com a irmã de Luciano, Rosana, Analba ultrapassa o discurso presente nas fontes documentais e retrata a história pontuando sentimentos e nuances que envolvem tal caso.

Com grande repercussão na mídia do Estado do Rio Grande do Norte, o fato aconteceu no mês de abril do ano de 1995. O mecânico Luciano, de 37 anos de idade, matou sua mulher, Suzana, de 28 anos, e atirou nos quatro filhos, levando à morte três deles. Sobreviveu a filha mais velha, porém, além dos traumas psicológicos, também ficou com sequelas físicas: perdeu a visão em decorrência do tiro que levou no rosto. Após os assassinatos Luciano tentou suicídio, não conseguindo no primeiro momento. Foi preso e internado no hospital público do Estado, no entanto, no dia do sepultamento de seus familiares, pulou do terceiro andar do hospital, efetivando seu objetivo de morrer.

Os jornais levantaram algumas possibilidades numa tentativa de justificar o caso: ciúme, dívidas financeiras, amor. $O$ discurso médico, através de análises de psiquiatras, está presente nas matérias jornalísticas, com objetivo de fixar a identidade de Luciano entre aqueles detentores de uma personalidade mórbida. O sepultamento das vítimas foi coberto pela mídia que, de forma sensacionalista, também expôs fotos dos corpos das vítimas.

A partir do cruzamento de várias fontes, Analba relata o caso da seguinte forma. O casal viveu maritalmente durante dezesseis anos. Casaram-se apaixonados e tiveram quatro filhos. Luciano, proprietário de uma oficina de carros, aparentava ser um homem tranquilo, equilibrado, bom pai de família e amigo dos funcionários, no entanto, era ciumento. A filha de Luciano sobrevivente da tragédia informa que o pai era "bom fora de casa", porém para a mãe dela era "outra pessoa". O ciúme imperava na relação e não se restringia apenas à mulher, estendendo-se às duas filhas. A bebida alcoólica também aparece como um motivo desencadeador das brigas constantes entre o casal, que sempre aconteciam na presença dos quatro filhos. Geralmente Suzana ia embora escondida pela madrugada com seus filhos depois das brigas, mas sempre retornava para casa, acreditando na mudança de comportamento do marido.

No dia da tragédia, Luciano, após brigar com Suzana por ciúmes, saiu e deixou a família em casa trancada. Não houve possibilidade de fuga. Quando retornou, dormiu e por volta das quatro horas da madrugada começou a eliminar um por um, começando pelo filho mais novo, Ronaldo, de um ano de idade, depois Sueli, de sete anos, e em seguida atirou em Antônio, que suplicava: não! não! Matou Suzana desferindo oito facadas e atirou no rosto de Andréia, a filha mais velha, que sobreviveu. Andréia, casada no período em que concedeu a entrevista, sofre por não poder enxergar seu filho, traz consigo sentimentos de pena, raiva e revolta do pai e reconhecia muitas vezes uma vontade enorme de morrer.

Este caso é apenas uma amostra da discussão presente no livro de Analba. Faz-nos refletir que, apesar das conquistas políticas efetivadas em torno da violência que atinge mulheres, ainda há muito a se fazer e muito para pesquisar. A contribuição de Analba é fundamental para pesquisas científicas, movimentos sociais e, consequentemente, poderá colaborar para possíveis formulações de políticas públicas na área que abrange a violência de gênero, em especial as violências perpetradas contra as mulheres. Esse fato acentua a identidade e 
compromisso científico e militante da autora, além de destacar sua contribuição para aumentar a visibilidade de problema tão ardiloso que atinge mulheres de idades, segmentos sociais, religiões e etnias diversificadas.

A autora conclui o estudo informando que muitas questões surgiram na construção da pesquisa e que necessitam de respostas. No entanto, aponta que o amor, o ciúme e a honra foram considerados, tanto nas narrativas encontradas quanto nas fontes documentais, a exemplo das entrevistas, como problemas que justificavam a prática de homicídio seguido do suicídio. Analba chama atenção para o fato de que tais fatores não devem ser considerados separadamente como "causas" principais dos homicídios seguidos de suicídios. Estes fatores devem ser conjugados e acompanhados de outros elementos como relações de gênero, masculinidades e feminilidades, além de uma leitura mais apurada dos fatores psicológicos que motivam crimes dessa natureza. Esses ingredientes, quando analisados juntamente, podem apontar para uma possível compreensão do jogo relacional que envolve o poder estabelecido entre os casais e que podem desembocar em tragédias semelhantes às apresentadas no livro, tragédias que povoam seguidamente os jornais de todas as regióes do Brasil.

\section{Notas}

1 BRASIL, 2006.

2 BRASIL, 2009.

\section{Referências bibliográficas}

BRASIL. Lei Maria da Penha. Lei 11.340, 2006. Lei Crime de Estupro. Lei 12.015, 2009.

Patrícia Rosalba Salvador Moura Costa Universidade Federal de Santa Catarina Miriam Pillar Grossi Universidade Federal de Santa Catarina 